\title{
Urogynecological conditions associated with overactive bladder symptoms in women
}

\author{
James C. Forde, MD; Jonathan L. Davila, MD;2 Brian K. Marks, MD;, Matthew Epstein, MD; \\ Johnson F. Tsui, MD, Jeffrey P. Weiss, MD;2,3 Jerry G. Blaivas, $M D^{123}$
}

'Deptartment of Urology, Weill Medical College of Cornell University, New York, NY, United States; ${ }^{2}$ Deptartment of Urology, SUNY Downstate Medical School, Brooklyn, NY, United States; ${ }^{3}$ Institute for Bladder and Prostate Research, New York, NY, United States

Cite as: Can Urol Assoc J 2017;11(3-4):E83-7. http://dx.doi.org/10.5489/cuaj.3962

Published online March 16, 2017

\section{Abstract}

Introduction: Overactive bladder symptoms (OAB) affect 9-43\% of women and are associated with underlying disorders, including pelvic organ prolapse (POP) and stress urinary incontinence (SUI). The aim of this study is to identify urogynecological conditions associated with OAB symptoms.

Methods: This prospective, institutional review board-approved study included women referred to a tertiary centre with lower urinary tract symptoms (LUTS). All women completed the selfadministered OAB questionnaire (OABSS). Those with an OABSS $\geq 8$, the cutoff, were considered to have OAB symptoms. Patients underwent a history and physical examination (including BadenWalker prolapse grading and stress test), 24-hour voiding diary, pad test (for urinary incontinence), urinalysis, and uroflow with post-void residual volume. Patients were classified clinically into the following: idiopathic OAB, SUI, POP, bladder outlet obstruction (BOO) neurogenic bladder (NGB), recurrent urinary tract infection (UTI), and miscellaneous.

Results: In total, 148 women met the inclusion criteria with a mean age of 67 years. Only $27 \%$ had no comorbid conditions and were considered idiopathic OAB. Associated urogynecological conditions included SUI in $37 \%$, POP in $26 \%$, miscellaneous conditions in $18 \%$, recurrent UTI in $11 \%, \mathrm{NGB}$ in $9 \%$, and BOO in $8 \%$. Some patients met criteria for more than one category, thus the total is greater than $100 \%$.

Conclusions: In a tertiary care setting, a significant proportion of women with $\mathrm{OAB}$ symptoms have underlying conditions that may cause or contribute to their symptoms. Appropriate evaluation is desirable to enhance our understanding of the relationship of these conditions to the diagnosis, treatment, outcomes, and pathophysiology of OAB.

\section{Introduction}

Up to $66 \%$ of community-based adult women report lower urinary tract symptoms (LUTS) ${ }^{1}$ and it has been estimated that
$9-43 \%$ have overactive bladder (OAB) ${ }^{1-5}$ The International Continence Society (ICS) defines OAB as "urgency, with or without urge incontinence, usually with frequency and nocturia" and now recognizes that OAB is a "symptom syndrome suggestive of lower urinary tract dysfunction." ${ }^{\prime 6}$ They recommend that the diagnosis of $\mathrm{OAB}$ should be restricted to those in whom urinary tract infection (UTI) and other pathology has been excluded. ${ }^{5}$ The aim of this study is define the "other pathology" that presents with OAB symptoms in a tertiary care setting.

In the original ICS terminology, the term OAB was combined with detrusor overactivity (DO). ${ }^{6} \mathrm{DO}$ is a urodynamic diagnosis, while OAB is a symptom complex; ${ }^{7}$ however, over time, the term DO incorrectly became used interchangeably with the term OAB. The ICS confirmed this was not their intent, ${ }^{6}$ as it is known that urodynamic DO is demonstrated in only $40-60 \%$ of patients with $\mathrm{OAB} \cdot{ }^{8,9} \mathrm{OAB}$ is diagnosed and managed at almost all levels of patient care, with a significant proportion of patients presenting to and being initially managed by their primary care provider. The guidelines for diagnosis and management of $O A B$ were published by the American Urological Association (AUA)/Society of Urodynamics, Female Pelvic Medicine and Urogenital Reconstruction (SUFU). ${ }^{5}$ The guidelines suggest a minimum diagnostic evaluation comprised of a history, physical exam, and urinalysis. The purpose of this evaluation is to document symptoms and signs that characterize $\mathrm{OAB}$ and exclude other disorders that could be the cause of the patient's symptoms. ${ }^{10}$ These confounding diagnoses are numerous and can include neurological diseases, mobility deficits, medically complicated or uncontrolled diabetes, a history of recurrent UTIs, prior pelvic/vaginal surgeries, pelvic cancer, pelvic radiation, and pelvic organ prolapse (POP).

Studies have shown that DO is present in other urological conditions, including stress urinary incontinence (SUI), POP, bladder outlet obstruction (BOO), impaired detrusor contractility, and neurogenic bladder (NGB). ${ }^{9}$ Patients with bladder cancer can also present with symptoms suggestive 
Forde et al.

of OAB. ${ }^{11}$ We have previously reported that $95 \%$ of men with $\mathrm{OAB}$ have associated urological pathology, the most common of which are benign prostatic hyperplasia $(\mathrm{BPH})$ and prostatic obstruction..$^{12}$ In this study, we explore the urogynecological conditions in women presenting with $\mathrm{OAB}$ symptoms in a tertiary care setting.

\section{Methods}

\section{Patient selection}

We performed an institutional review board-approved, observational, descriptive study to identify underlying comorbid conditions associated with $\mathrm{OAB}$ symptoms. Patients were selected from consecutive women who attended a tertiary outpatient urology referral centre from January 1, 2014 to June 1, 2015 with a chief complaint of LUTS and who completed the Overactive Bladder Symptom Score (OABSS) questionnaire. ${ }^{13}$ Those with an OABSS $\geq 8$, the cutoff for $\mathrm{OAB}$, were included in the study. All patients underwent an extensive history and physical examination (including BadenWalker prolapse grading and stress test), a 24-hour voiding diary and pad test (for those with incontinence), urinalysis, uroflowmetry, and determination of post-void residual urine volume. Selected patients underwent urodynamics and cystoscopy. On the basis of this evaluation, patients were classified clinically into one of the following groups: idiopathic $\mathrm{OAB}, \mathrm{SUI}, \mathrm{POP}, \mathrm{NGB}$, recurrent UTI, and miscellaneous.

\section{Criteria for urogynecological diagnoses}

SUI was diagnosed by history and/or demonstrable leakage of urine during cough or Valsalva maneuver with a full bladder on exam and/or urodynamic confirmation of SUI. POP was diagnosed by history and physical examination with a full bladder in the lithotomy position and the grade was evaluated using the Baden-Walker prolapse grading. NGB was diagnosed in patients with a neurological condition known to affect the lower urinary tract, including spinal injury, cerebral vascular accident, Parkinson's disease, multiple sclerosis, and myelopathy. Urethral obstruction was diagnosed by the Blaivas-Groutz nomogram. ${ }^{14}$ Recurrent UTI was defined as the persistence of OAB symptoms in patients with three or more episodes of bacterial cystitis in the previous year after undergoing successful antibiotic treatment, as documented by negative urine cultures. Urethral diverticula were diagnosed by voiding cystourethrogram performed at the time of videourodynamics or by magnetic resonance imaging $(\mathrm{MRI})$. Patients who presented with acute cystitis and whose symptoms abated upon appropriate antimicrobial therapy were excluded.

\section{Results}

During the observation period, 195 women with LUTS completed the OABSS. Of these, $148(76 \%)$ had an OABSS $\geq 8$, the cutoff for $O A B$, and were included in the study. Their mean age was 67.3 years (range 20-92). OAB was the most bothersome LUTS in 93 patients (63\%) and was their chief complaint in $41 \%$ (61 patients). Cystoscopy and videourodynamics were performed in 105 patients $(71 \%)$. DO was demonstrated in 53 patients (50\%) who underwent urodynamics.

The urogynecological conditions associated with $\mathrm{OAB}$ symptoms are listed in Table 1 and included SUI in 37\%, POP in $26 \%$, miscellaneous conditions in $18 \%$, recurrent UTI in $11 \%, \mathrm{NGB}$ in $9 \%$, and $\mathrm{BOO}$ in $8 \%$. Some patients met criteria for more than one diagnostic category, thus the total is greater than $100 \%$. Overall, 27 patients (18\%) were classified as miscellaneous urogynecological conditions and are listed in Table 2. Only 27\% of patients had idiopathic OAB without any other associated urogynecological diagnosis.

Of the 38 women with prolapse, the Baden-Walker grade was Grade 1 in five patients (13\%), Grade 2 in 17 (45\%), Grade 3 in $14(37 \%)$, and Grade 4 in $2(5.0 \%)$. The mean OABSS for the entire cohort was 15.5 for 148 patients. The mean OABSS for each diagnostic category is detailed in Table 1.

\section{Discussion}

It has been estimated that $9-43 \%$ of adult women in the general population have OAB..$^{1-5}$ It is well-recognized that $\mathrm{OAB}$ symptoms are common in other conditions, such as prostatic obstruction in men ${ }^{12}$ and Grade 3 and 4 prolapse in women. ${ }^{15}$ According to the ICS, patients with persistent OAB symptoms unaccompanied by hematuria or pyuria should be diagnosed with $\mathrm{OAB}$, provided there is no "infection or other proven etiology." The AUA/SUFU OAB guidelines provide a detailed discussion of what comprises "other proven etiolog(ies)," ${ }^{5}$ but there is a paucity of studies that actually quantify the incidence of those other etiologies among patients presenting with $\mathrm{OAB}$ symptoms. This data is important because, in our judgment, many physicians, particularly those in primary care, do no more than the cursory evaluation recommended by the AUA/SUFU guidelines and assume the preponderance have idiopathic OAB. This may subject patients to unnecessary, ineffective treatments and deny them early treatment of remediable conditions, such as high-grade POP.

In this series, $73 \%$ of women had underlying pathologies that might contribute to their OAB symptoms. Only $27 \%$ of patients had true idiopathic OAB. Twenty six percent of women in our study with $\mathrm{OAB}$ symptoms had POP. Romanzi et al first noted the association between POP and DO.${ }^{15}$ In that study, $52 \%$ of women with Grade 3 and 4 prolapse demonstrated 


\begin{tabular}{|c|c|c|c|c|}
\hline Diagnosis & $\begin{array}{c}\text { Number } \\
(\%)\end{array}$ & $\begin{array}{l}\text { Mean } \\
\text { OABSS }\end{array}$ & $\begin{array}{l}\text { Median } \\
\text { OABSS }\end{array}$ & SD \\
\hline $\begin{array}{l}\text { Sphincteric } \\
\text { incontinence/SUI }\end{array}$ & $55(37.2)$ & 16.4 & 17 & 5.3 \\
\hline Idiopathic & $40(27.0)$ & 14.5 & 15 & 4.4 \\
\hline Pelvic organ prolapse & $38(25.7)$ & 14.7 & 14 & 5 \\
\hline Miscellaneous & $27(18.2)$ & 15.3 & 15 & 4.2 \\
\hline Urinary tract infection & $17(11.5)$ & 15.3 & 15 & 5.3 \\
\hline Neurogenic bladder & $13(8.8)$ & 18.2 & 19 & 5.6 \\
\hline $\begin{array}{l}\text { Bladder outlet } \\
\text { obstruction }\end{array}$ & $12(8.1)$ & 15.4 & 16 & 4.8 \\
\hline Total & $201(136.5)$ & 15.5 & 15 & 5 \\
\hline
\end{tabular}

Each subject could be represented in more than one diagnostic category, excluding the idiopathic category; thus, the total is greater than $100 \%$. OABSS: overactive bladder symptom score; SD: standard deviation; SUl: stress urinary incontinence.

DO vs. $20 \%$ with Grade 1 and 2, a significant difference. ${ }^{15}$ Foster et al demonstrated that $66 \%$ of patients with Grade 3 and 4 POP experienced urgency symptoms, 25\% had DO on preoperative urodynamics, and correction with pelvic surgery led to a resolution of symptoms in $55-75 \%$ at one year. ${ }^{16}$ In this series, $42 \%$ of the patients with POP were Grade 3-4; however, OAB symptoms were present even in those with less severe prolapse. Other investigators have found a significant improvement in $\mathrm{OAB}$ symptoms up to $53-82 \%$ following surgical repair of POP. ${ }^{17,18}$ Of course, the mere presence of POP is not an indication for any treatment at all; it is a quality-oflife decision. Nevertheless, we believe that for patients with Grade 3 and 4 POP with refractory OAB, surgical treatment offers the best chance of symptom amelioration.

Eight per cent of the patients in this series had BOO. The association of $\mathrm{OAB}$ symptoms with $\mathrm{BOO}$ has been well-documented in men with prostatic obstruction, and relief of obstruction ameliorates the OAB symptoms in most patients. ${ }^{19}$ It is estimated that $50-75 \%$ of men with $\mathrm{BOO}$ on urodynamics have OAB symptoms ${ }^{20}$ and up to $47 \%$ have demonstrable DO. ${ }^{21}$ Similarly in women, OAB is the presenting symptom in up to $75-90 \%$ of patients with BOO following anti-incontinence surgery. ${ }^{22,23}$ Relief of this iatrogenic obstruction has been shown to improve or cure in $\mathrm{OAB}$ symptoms for the majority of women. ${ }^{23,24}$ This highlights the importance of recognizing the underlying urogynecological conditions associated with the OAB symptom complex and the need to direct therapy to the underlying cause.

The majority of patients in our study $(70 \%)$ underwent urodynamics. DO was demonstrated in 53 of these patients $(50 \%)$. These findings are consistent with other studies where urodynamic DO is demonstrated in $40-60 \%$ of patients. ${ }^{8,9} \mathrm{In}$ this series, $37 \%$ of patients had SUI in addition to OAB. This is not surprising, as mixed stress and urge incontinence is evident in up to $50 \%$ of women with incontinence, ${ }^{25,26}$ and approximately $18-67 \%$ of these patients have DO on uro-

\begin{tabular}{lc}
\hline Table 2. Miscellaneous diagnoses with OABSS $\mathbf{\geq 8}(\mathbf{N}=\mathbf{2 7})$ \\
\hline Urethrovaginal fistula & 1 \\
Urethral caruncle & 3 \\
Urethral mesh sling & 7 \\
Bladder cancer & 4 \\
Vesicovaginal fistula & 1 \\
Pubovaginal sling & 4 \\
Urethral diverticulum & 2 \\
Periurethral mass & 1 \\
Mesh erosion & 2 \\
Bladder lipoma & 1 \\
Urethral cyst & 1 \\
\hline OABSS: overactive bladder symptom score. &
\end{tabular}

dynamic evaluation. ${ }^{25-28}$ Following sling surgery, studies have shown a resolution rate of $23-93 \%$ of OAB symptoms, ${ }^{27,29}$ and a resolution of $31 \%$ in demonstrable DO. ${ }^{28}$

It is well-known that neurological conditions are frequently accompanied by OAB symptoms and neurogenic DO. ${ }^{30}$ Other non-neurogenic causes of $O A B$ symptoms include infection, bladder tumour, and bladder stones. ${ }^{30,31}$ As identified in the present study, bladder cancer, even in the absence of hematuria, may present as OAB in women. The clinician should consider this diagnosis because not all bladder cancer presents with hematuria; sometimes, the only symptoms are those of OAB. ${ }^{11,32}$ In $18.2 \%$, other less common conditions were identified. The majority $(26 \%)$ had OAB after implantation of a synthetic mesh sling. De novo $O A B$ is a known complication of suburethral sling insertion and the incidence had been reported to vary from $3.1-25.9 \% .^{33-37}$ In patients with refractory $O A B$, sling excision was found to relieve the OAB symptoms in $28-64 \%$ of patients. ${ }^{38}$

In our opinion, identifying underlying causes of $O A B$ symptoms should occur before empiric $O A B$ therapies begin. In fact, this is exactly what the AUA guideline panel recommended. ${ }^{6}$ To this end, it is important to be sure that the history and physical examination is sufficient to evaluate for the possibility of all of the conditions described above and we also recommend the routine use of a bladder diary. SUI and high-grade POP should be excluded by history and exam. We also recommend that uroflowmetry and post-void residual urine be considered an integral part of the initial evaluation because there is no other way to screen for bladder outlet obstruction. In a prior publication, the authors demonstrated that over $90 \%$ of men with OAB symptoms have concomitant urological conditions that should be considered in the differential diagnosis. ${ }^{12}$ The present study demonstrates a similar pattern in women; $73 \%$ had other urologynecological diagnoses that presented with symptoms of OAB.

This study suffers from both the limitations of a singleinstitution and retrospective analysis. Firstly, the sample size is relatively small. Secondly, the patients were seen at a tertiary referral centre for voiding dysfunction and, thus, this 
Forde et al.

sample may not represent those patients found in the general population. Accordingly, the breakdown of the comorbid conditions may not be applicable to other patient populations. However, previous studies in men have demonstrated that the pathophysiology of LUTS in a specialized centre may be representative of those in a primary urological setting. ${ }^{21}$ This study is not the first to describe other urological pathologies as coexisting or causing $\mathrm{OAB}^{11}$ however, we primarily sought to emphasize that symptoms suggestive of $\mathrm{OAB}$ may coincide/present with other urological conditions and complete investigation is necessary before a diagnosis of $\mathrm{OAB}$ is made and relevant treatment commenced.

\section{Conclusion}

The majority of women with symptoms of $O A B$ have an underlying urogynecological condition, many of which are remediable to specific medical or surgical treatment. Most $\mathrm{OAB}$ guidelines suggest a stepwise, algorithmic approach to the diagnosis; however, a more thorough evaluation, as outlined in this study, even in primary urology and urogynecology settings, would likely lead to an earlier diagnosis and definitive treatment of conditions such as BOO and POP, thus avoiding unnecessary empirical treatments.

Competing interests: Dr. Weiss has served as an advisor for Allergan, Astellas, Ferring, Pfizer, and Vantia. Dr. Blaivas is cofounder and CSO of Symptelligence Medical Informatics. The remaining authors report no competing personal or financial interests.

Acknowledgements: As the clinical fellow in voiding dysfunction at Weill Cornell Medical College, Dr. Forde is supported by The Frederick J. and Theresa Dow Wallace Fund of the New York Community Trust.

This paper has been peer-reviewed.

\section{References}

1. Irwin DE, Milsom I, Hunskaar S, et al. Population-based survey of urinary incontinence, overactive bladder, and other lower urinary tract symptoms in five countries: Results of the EPIC study. Eur Urol 2006;50:130614. https://doi.org/10.1016/i.eururo.2006.09.019

2. Milsom I, Abrams $P$, Cardozo $L$, et al. How widespread are the symptoms of an overactive bladder and how are they managed? A population-based prevalence study. BJU Int 2001; 87:760-6. https://doi.org/10.1046/i.1464-410x.2001.02228.x

3. Stewart WF, Van Rooyen JB, Cundiff GW, et al. Prevalence and burden of overactive bladder in the United States. World J Urol 2003;20:327-36.

4. Wennberg AL, Molander U, Fall M, et al. A longitudinal population-based survey of urinary incontinence, overactive bladder, and other lower urinary tract symptoms in women. Eur Urol 2009;55:783-91. https://doi.org/10.1016/i.eururo.2009.01.007

5. Gormley EA, Lightner DJ, Faraday $M$, et al. Diagnosis and treatment of overactive bladder (non-neurogenic) in adults: AUA/SUFU guideline amendment. J Urol 2015;193:1572-80. https://doi.org/10.1016/i. juro.2015.01.087

6. Wein AJ, Rovner ES. Definition and epidemiology of overactive bladder. Urology 2002;60:7-12. https://doi.org/10.1016/S0090-4295(02)01784-3
7. Abrams P, Cardozo L, Fall M, et al for the Standardization Sub-committee of the International Continence. The standardization of terminology of lower urinary tract function: Report from the Standardization Sub-committee of the International Continence Society. Neurourol Urodyn 2002;21:167-78. https://doi.org/10.1002/nau.10052

8. Blaivas IG, Groutz A, Verhaaren M. Does the method of cystometry affect the incidence of involuntary detrusor contractions? A prospective, randomized, urodynamic study. Neurourol Urodyn 2001;20:141-5. https://doi.org/10.1002/1520-6777(2001)20:2<141::AlD-NAU16>3.0.C0;2-P

9. Flisser AJ, Walmsley K, Blaivas IG. Urodynamic classification of patients with symptoms of overactive bladder. J Urol 2003;169:529-33. https://doi.org/10.1016/S0022-5347(05)63948-1

10. Gormley EA, Lightner DJ, Burgio KL, et al. Diagnosis and treatment of overactive bladder (non-neurogenic) in adults: AUA/SUFU guideline. J Urol 2012;188:2455-63. https://doi.org/10.1016/i.juro.2012.09.079

11. Nitti V, Taneja $S$. Overactive bladder: Achieving a differential diagnosis from other lower urinary tract conditions. Int I Clin Pract 2005;59:825-30. https://doi.org/10.1111/j.1742-1241.2005.00490.x

12. Blaivas JG, Marks BK, Weiss JP, et al. Differential diagnosis of overactive bladder in men. J Urol 2009;182:2814-7. https://doi.org/10.1016/i.juro.2009.08.039

13. Blaivas JG, Panagopoulos $G$, Weiss JP, et al. Validation of the overactive bladder symptom score. J Urol 2007;178:543-7. https://doi.org/10.1016/i.juro.2007.03.133

14. Blaivas JG, Groutz A. Bladder outlet obstruction nomogram for women with lower urinary tract symptomatology. Neurourol Urodyn 2000;19:553-64. https://doi.org/10.1002/1520-6777(2000) 19:5<553::AIDNAU2 $>3.0 . C 0 ; 2-B$

15. Romanzi $\amalg$, Chaikin DC, Blaivas JG. The effect of genital prolapse on voiding. J Urol 1999;161:581-6. https://doi.org/10.1016/S0022-5347(01)61957-8

16. Foster RT Sr, Barber MD, Parasio MF, et al. A prospective assessment of overactive bladder symptoms in a cohort of elderly women who underwent transvaginal surgery for advanced pelvic organ prolapse. Am J Obstet Gynecol 2007;197:82 el-4.

17. Basu M, Duckeft J. Effect of prolapse repair on voiding and the relationship to overactive bladder and detrusor overactivity. Int Urogynecol J Pelvic Floor Dysfunct 2009;20:499-504. https://doi.org/10.1007/ s00192-009-0807-z

18. Digesu $G A$, Salvatore $S$, Chaliha $C$, et al. Do overactive bladder symptoms improve after repair of anterior vaginal wall prolapse? Int Urogynecol J Pelvic Floor Dysfunct 2007; 18:1439-43. https://doi.org/10.1007/s00192-007-0375-z

19. Kageyama $S$, Watanabe $\mathrm{T}$, Kurita $\mathrm{Y}$, et al. Can persisting detrusor hyperreflexia be predicted after transurethral prostatectomy for benign prostatic hypertrophy? Neurourol Urodyn 2000;19:233-40. https://doi.org/10.1002/(SICI) 1520-6777(2000) 19:3<233::AID-NAU4>3.0.C0;2-M

20. Ameda K, Sullivan MP, Bae RJ, et al. Urodynamic characterization of non-obstructive voiding dysfunction in symptomatic elderly men. J Urol 1999;162:142-6. https://doi.org/10.1097/00005392-19990700000035

21. Fusco F, Groutz A, Blaivas IG, et al. Videourodynamic studies in men with lower urinary tract symptoms: A comparison of community-based vs. referral urological practices. J Urol 2001;166:910-3. https://doi.org/10.1016/S0022-5347(05)65862-4

22. Carr LK, Webster GD. Voiding dysfunction following incontinence surgery: Diagnosis and treatment with retropubic or vaginal urethrolysis. J Urol 1997;157:821-3. https://doi.org/10.1016/S0022$5347(01) 65054-7$

23. Starkman JS, Duffy JW 3rd, Wolter CE, et al. The evolution of obstruction-induced overactive bladder symptoms following urethrolysis for female bladder outlet obstruction. J Urol 2008;179:1018-23. htrps://doi.org/10.1016/i.juro.2007.10.051

24. Leng WW, Davies BJ, Tarin T, et al. Delayed treatment of bladder outlet obstruction after sling surgery: Association with irreversible bladder dysfunction. J Urol 2004;172:1379-81. htrps://doi.org/10.1097/01.ju.0000138555.70421.ca

25. Chou EC, Blaivas $I G$, Chou $L W$, et al. Urodynamic characteristics of mixed urinary incontinence and idiopathic urge urinary incontinence. Neurourol Urodyn 2008;27:376-8. https://doi.org/10.1002/nau.20536

26. Digesu GA, Salvatore $S$, Fernando R, et al. Mixed urinary symptoms: What are the urodynamic findings? Neurourol Urodyn 2008;27:372-5. https://doi.org/10.1002/nau.20530

27. Choe JH, Choo MS, Lee KS. The impact of tension-free vaginal tape on overactive bladder symptoms in women with stress urinary incontinence: Significance of detrusor overactivity. J Urol 2008;179:214-9. https://doi.org/10.1016/i.juro.2007.08.151

28. Gamble TL, Botros SM, Beaumont JL, et al. Predictors of persistent detrusor overactivity after transvaginal sling procedures. Am J Obstet Gynecol 2008;199:696 el-7.

29. Duckett JR, Basu M. The predictive value of preoperative pressure-flow studies in the resolution of detrusor overactivity and overactive bladder after tension-free vaginal tape insertion. BJU Int 2007;99:1439-42. https://doi.org/10.1111/i.1464-410X.2007.06842.x

30. Wein AJ, Rackley RR. Overactive bladder: A better understanding of pathophysiology, diagnosis and management. J Urol 2006;175:S5-10. https://doi.org/10.1016/S0022-5347(05)00313-7

31. Blaivas JG. The neurophysiology of micturition: A clinical study of 550 patients. J Urol 1982; 127:958-63. 
Urogynecological conditions associated with $\mathrm{OAB}$ symptoms

32. Kaufman DS, Shipley WU, Feldman AS. Bladder cancer. Lancet 2009;374:239-49. https://doi.org/10.1016/S0140-6736(09)60491-8

33. Kershen RT, Appell RA. De novo urge syndrome and detrusor instability after anti-incontinence surgery: Current concepts, evaluation, and treatment. Curr Urol Rep 2002;3:345-53. https://doi.org/10.1007/ s1 1934-002-0075-7

34. Collinet P, Ciofu C, Costa P, et al. The safety of the inside-out transobturator approach for transvaginal tape (TVT-0) treatment in stress urinary incontinence: French registry data on 984 women. Int Urogynecol J Pelvic Floor Dysfunct 2008;19:711-5. https://doi.org/10.1007/s00192-007-0514-6

35. Celebi I, Gungorduk K, Ark C, et al. Results of the tension-free vaginal tape procedure for treatment of female stress urinary incontinence: a 5-year followup study. Arch Gynecol Obstet 2009;279:463-7. https://doi.org/10.1007/s00404-008-0805-2
36. Lee KS, Choo MS, Doo CK, et al. The long term (5-years) objective TVT success rate does not depend on predictive factors at multivariate analysis: A multicenter, retrospective study. Eur Urol 2008;53:176-82. https://doi.org/10.1016/j.eururo.2007.08.033

37. Giberti C, Gallo F, Cortese $P$, et al. Transobturator tape for treatment of female stress urinary incontinence: Objective and subjective results after a mean followup of two years. Urology 2007;69:703-7. https://doi.org/10.1016/i.urology.2007.01.013

38. Blaivas JG, Purohit RS, Benedon MS, et al. Safety considerations for synthetic sling surgery. Nat Rev Urol 2015;12:481-509. https://doi.org/10.1038/nrurol.2015.183

Correspondence: Dr. James C. Forde, Department of Urology, Weill Cornell Medicine, New York, NY, United States; jif9007@med.cornell.edu 